\title{
Phase 2 Trial of V-5 Immunitor (V5) in Patients with Chronic Hepatitis C Co-infected with HIV and Mycobacterium tuberculosis
}

\author{
Olga V. Arjanova ${ }^{1}$, Nathalia D. Prihoda ${ }^{1}$, Larisa V. Yurchenko', Nina I. Sokolenko', Valery M. Frolov², Marina G Tarakanovskaya ${ }^{3}$, Vichai \\ Jirathitikal ${ }^{4}$ and Aldar S. Bourinbaiar ${ }^{5 *}$
}

${ }^{1}$ Lisichansk Regional Tuberculosis Dispensary, Lisichansk, Ukraine

2Luhansk State Medical University, Luhansk, Ukraine

${ }^{3}$ Ekomed LLC, Ulaanbaatar, Mongolia

${ }^{4}$ Immunitor Thailand Co., LLC

5Immunitor USA Inc., College Park, MD 20740, USA

\begin{abstract}
Summary
V-5 Immunitor (V5) has been evaluated in patients with chronic hepatitis $\mathrm{C}$ with concomitant HIV and Mycobacterium tuberculosis infections. Once-daily tablet of V 5 was administered per os to 20 patients for one month. Every patient who entered the study had enlarged liver, elevated hepatic damage markers, which at the end of study have improved in 19 out $20(95 \%)$ patients. The reduction was highly significant, from $1.72 \pm 0.34$ to $0.18 \pm 0.28 \mu \mathrm{mol} / \mathrm{ml} \cdot \mathrm{h}(\mathrm{P}=5.0 \mathrm{E}-012)$ and $22.1 \pm 3.4$ to $10.9 \pm 2.5 \mu \mathrm{M} / \mathrm{L}(\mathrm{P}=5.7 \mathrm{E}-009)$ for $\mathrm{ALT}$ and total bilirubin respectively. Enlarged liver reduced from $3.5 \pm 1.4$ to $0.95 \pm 1.1 \mathrm{~cm}$ above normal size $(\mathrm{P}=2.9 \mathrm{E}-009)$. As patients were hospitalized in TB hospital they were treated with standard anti-TB therapy (ATT) in addition to V5. Surprisingly, V5 appeared to contribute to higher and faster than expected sputum conversion rate; $94.4 \%$ of smear-positive patients became negative within one month. TB-associated fever subsided within mean/median $4.1 / 3$ days; indicators of inflammation such as elevated erythrocyte sedimentation rate and high leukocyte counts returned back to normal from $32.3 \pm 11.4$ to $9.9 \pm 6.4 \mathrm{~mm} / \mathrm{h}(P=3.7 \mathrm{E}-008)$ and $14.3 \pm 3.9$ to $4.7 \pm 1.4 \times 109 \mathrm{~L}(\mathrm{P}=7.1 \mathrm{E}-010)$ respectively. Average body weight gain was $7.7 \mathrm{~kg}(\mathrm{P}=4.6 \mathrm{E}-007)$ and hemoglobin levels increased from $114 \pm 7.1$ to $123.4 \pm 6.6 \mathrm{~g} / \mathrm{L}(\mathrm{P}=1.4 \mathrm{E}-007)$. No adverse events were observed at any time. After one month 17 out of 20 patients were deemed cured from TB and discharged from the dispensary. Further studies are needed to confirm this preliminary observation suggesting that in addition to the beneficial effect in managing chronic hepatitis, V5 might also be useful as a safe and effective means for immunotherapy of tuberculosis.
\end{abstract}

Keywords: Mucosa; Therapeutic vaccine; Immunomodulation; HCV; TB; HIV

\section{Introduction}

Hepatitis $\mathrm{C}$ virus $(\mathrm{HCV})$ is a global public health problem, affecting an estimated 180 million people [1]. The current standards of care are interferon alpha or pegylated interferons alone or in combination with ribavirin. However, they have shown limited success and are associated with undesirable side effects $[1,2]$. The high cost of medications is another barrier that prevents wider use of anti-HCV therapy, especially in developing countries. Thus, the treatment of chronic HCV infection represents an unmet medical need. This problem is further aggravated when patients are co-infected with TB and/or HIV. It is agreed that the resurgence in the incidence of global TB is due in part to the AIDS epidemic. There are 9.2 million new cases and 1.7 million deaths from $\mathrm{TB}$ annually. According to various sources between one-third and one-half of patients with $T B$ are infected with HIV, which is associated with very poor prognosis and high mortality. Despite the overwhelming burden of disease, no new anti-TB compounds were developed in last 40 years and current strains of TB are becoming increasingly resistant to existing drugs. The occurrence of chronic hepatitis $\mathrm{C}$ along with TB and HIV in the same patient presents a challenging task with practically no therapeutic solution [2]. One of promising treatment approaches being pursued by many investigators around the world is so-called therapeutic vaccination, whereby the immune system of a host is modulated to fight off an infectious pathogen [3].

In previous studies, conducted in Mongolia, we have shown that oral therapeutic hepatitis vaccine V-5 Immunitor (V5), was beneficial to patients with hepatitis $B$ and hepatitis $C[4,5]$. The anecdotal evidence that became apparent during these investigations suggested that V5 could be beneficial to TB patients as well. In order to confirm these observations we have undertaken an independent study in Ukraine by recruiting patients with chronic hepatitis C. Due to fortuitous circumstances this study was carried out at a TB hospital with extensive experience in TB immunotherapy and hence the enrolled patients had concomitant Mycobacterium tuberculosis infection [6-8]. Furthermore, all individuals in this patient population were infected with HIV, which is common among individuals who acquire these infections through needle sharing practice. Neither AIDS therapy, nor HIV monitoring was carried out during this study since patients hospitalized in TB dispensaries in Ukraine are cared for TB only. Thus, even though our study was aimed at evaluating the effect of V5 in HCV patients it happened that they were also treated with standard anti-TB drugs (ATT).

\section{Materials and Methods}

\section{Subjects}

Five female and 15 male patients with chronic hepatitis $C$ infection were enrolled into open-label, one-month study. After

*Corresponding author: Aldar S. Bourinbaiar, Immunitor USA Inc., College Park, MD 20740, USA, Tel: 1301 476-0930; Fax: 1775 640-6636; E-mail: info@ immunitor.com

Accepted September 29, 2010; Published October 09, 2010

Citation: Arjanova OV, Prihoda ND, Yurchenko LV, Sokolenko NI, Frolov VM, et al. (2010) Phase 2 Trial of V-5 Immunitor (V5) in Patients with Chronic Hepatitis C Co-infected with HIV and Mycobacterium tuberculosis. J Vaccines Vaccin 1: 103 doi:10.4172/2157-7560.1000103

Copyright: () 2010 Arjanova OV, et al. This is an open-access article distributed under the terms of the Creative Commons Attribution License, which permits unrestricted use, distribution, and reproduction in any medium, provided the original author and source are credited. 
Citation: Arjanova OV, Prihoda ND, Yurchenko LV, Sokolenko NI, Frolov VM, et al. (2010) Phase 2 Trial of V-5 Immunitor (V5) in Patients with Chronic Hepatitis C Co-infected with HIV and Mycobacterium tuberculosis. J Vaccines Vaccin 1: 103. doi:10.4172/2157-7560.1000103

Page 2 of 5

ethical approval by the internal review board of the Lisichansk TB Dispensary, patients who had higher than normal baseline liver enzyme transaminase ALT and bilirubin levels were enrolled into the trial. All patients were hospitalized and presented with fever and cough and other common TB symptoms such as chest pain, dyspnea, hemoptysis, weight loss and anorexia. The median age of patients was 34.5 years, range 24-74 years, mean \pm SD equal to $36.1 \pm 10.6$ years. All patients were positive for hepatitis $C$ antibodies and anti-HIV antibodies as well (ACON Biotech, Hangzhou, PRC). The number of patients with first diagnosed TB, HCV, and HIV was 8,5 , and 8 respectively. The average/median duration of TB, HCV, and HIV infections prior to study initiation was $3.9 / 4,2.2 / 2$, and 2.5/2 years respectively (Figure 1 ). None of the patients were treated with interferon and/or anti-hepatitis drugs before or during the trial. Patients received standard or individualized ATT but no HIV therapy.

\section{V-5 Immunitor (V5)}

V5 is derived from pooled blood of hepatitis B and C carriers by employing proprietary technology developed by us. The process of manufacturing is described in detail earlier [3] - it involves heat- and chemical inactivation with subsequent formulation into a tablet. The principle for production of $\mathrm{V} 5$ is not much different from established

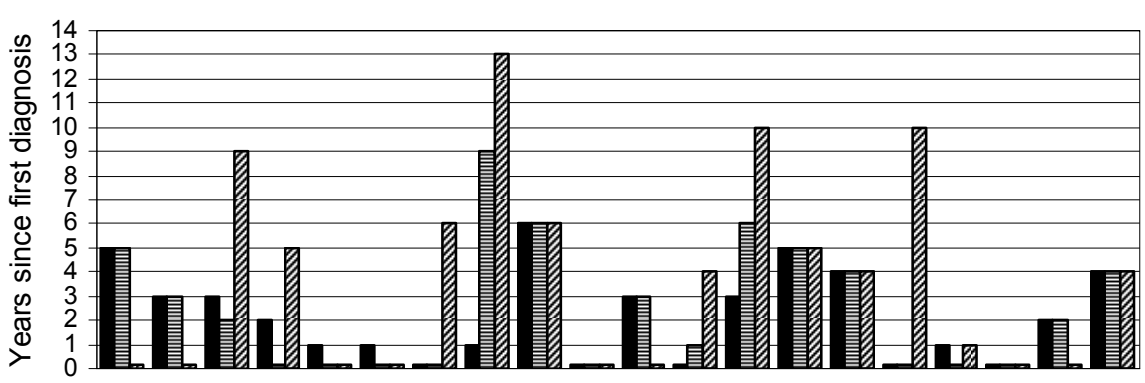

$\begin{array}{llllllllllllllllllll}1 & 2 & 3 & 4 & 5 & 6 & 7 & 8 & 9 & 10 & 11 & 12 & 13 & 14 & 15 & 16 & 17 & 18 & 19 & 20\end{array}$

Patient number

- HCV 目 HIV 四 TB

Figure 1: Duration of HCV, HIV and TB infections in enrolled patient population ( $\mathrm{N}=20)$ prior to V5 administration.

\begin{tabular}{|c|c|c|c|c|c|c|c|c|c|c|c|c|c|c|c|c|c|c|c|c|}
\hline \multirow{2}{*}{ No./Case No. } & \multirow{2}{*}{ Sex } & \multirow{2}{*}{ Age } & \multirow{2}{*}{\begin{tabular}{|l|} 
TB \\
drugs \\
regimen
\end{tabular}} & \multirow{2}{*}{\begin{tabular}{|l|} 
Months \\
treated \\
with \\
ATT \\
prior to \\
V5 \\
\end{tabular}} & \multicolumn{2}{|c|}{\begin{tabular}{|l} 
Smear \\
Positive
\end{tabular}} & \multicolumn{2}{|c|}{\begin{tabular}{|l} 
Liver size \\
in cm over \\
normal \\
\end{tabular}} & \multicolumn{2}{|c|}{$\begin{array}{l}\text { Erythrocyte } \\
\text { sedimentation } \\
\text { rate (ESR) }\end{array}$} & \multicolumn{2}{|c|}{$\begin{array}{l}\text { Leukocyte } \\
\times 10^{9} \mathrm{~L}\end{array}$} & \multicolumn{2}{|l|}{$\begin{array}{l}\mathrm{Hb} \\
\mathrm{g} / \mathrm{L}\end{array}$} & \multicolumn{2}{|l|}{$\begin{array}{l}\text { Weight } \\
\text { change } \\
\text { kg }\end{array}$} & \multicolumn{2}{|c|}{$\begin{array}{l}\text { Total } \\
\text { bilirubin } \\
\mu \mathrm{mol} / \mathrm{L}\end{array}$} & \multicolumn{2}{|c|}{$\begin{array}{l}\text { ALT }^{*} \\
\mu \mathrm{mol} / \mathrm{ml} \cdot \mathrm{h}\end{array}$} \\
\hline & & & & & before & after & before & after & before & after & before & after & before & after & before & after & before & after & before & after \\
\hline $1 / 602$ & $M$ & 33 & RZSE & 1 & - & - & 3 & 0 & 31 & 5 & 4.3 & 3.8 & 114 & 129 & 57 & 66 & 20 & 10 & 2.35 & 0.12 \\
\hline $2 / 57$ & $\mathrm{~F}$ & 24 & HRZSE & 4 & + & - & 7 & 2 & 58 & 9 & 11.6 & 4.3 & 101 & 118 & 62 & 75 & 25 & 10 & 1.62 & 0.12 \\
\hline $3 / 376$ & $M$ & 33 & HRZSE & 6 & + & - & 5 & 2 & 22 & 4 & 18.3 & 6 & 112 & 125 & 68 & 79 & 18 & 12 & 1.62 & 0.12 \\
\hline $4 / 78$ & $M$ & 42 & HRZSE & 2 & + & - & 4 & 1 & 32 & 5 & 14 & 6.8 & 118 & 128 & 74 & 86 & 13 & 15 & 2.35 & 0.12 \\
\hline $5 / 391$ & $\mathrm{M}$ & 74 & HRZSE & 6 & + & - & 4 & 1 & 22 & 7 & 12.3 & 2.8 & 120 & 132 & 72 & 82 & 25 & 10 & 1.62 & 0.1 \\
\hline $6 / 563$ & $\mathrm{~F}$ & 24 & HRZSE & 2 & + & - & 2 & 0 & 43 & 11 & 12 & 3.4 & 108 & 115 & 49 & 59 & 20 & 10 & 1.62 & 0.12 \\
\hline $7 / 422$ & $M$ & 36 & HRZSE & 5 & + & + & 4 & 4 & 28 & 32 & 14 & 3.8 & 112 & 110 & 62 & 54 & 20 & 20 & 1.62 & 1.38 \\
\hline $8 / 502$ & $\mathrm{M}$ & 34 & HRZSE & 3 & + & - & 5 & 1 & 32 & 10 & 20 & 6 & 108 & 116 & 67 & 74 & 25 & 10 & 1.62 & 0.12 \\
\hline $9 / 553$ & $M$ & 31 & HRZSE & 3 & + & - & 5 & 2 & 43 & 18 & 12 & 6 & 120 & 132 & 71 & 83 & 25 & 10 & 1.62 & 0.12 \\
\hline $10 / 579$ & $F$ & 34 & HRZSE & 3 & + & - & 2 & 0 & 40 & 10 & 14.9 & 4 & 112 & 120 & 47 & 52 & 25 & 10 & 1.62 & 0.12 \\
\hline $11 / 360$ & $M$ & 38 & HRZSE & 5 & - & - & 2 & 0 & 45 & 9 & 12 & 4 & 118 & 122 & 75 & 83 & 20 & 10 & 2.35 & 0.12 \\
\hline $12 / 570$ & $M$ & 36 & HRZSE & 3 & + & - & 2 & 0 & 28 & 7 & 19 & 5 & 122 & 128 & 60 & 70 & 25 & 10 & 1.62 & 0.12 \\
\hline $13 / 605$ & $M$ & 42 & HRZSE & 1 & + & - & 4 & 1 & 28 & 10 & 18 & 4 & 104 & 118 & 66 & 75 & 25 & 10 & 1.62 & 0.12 \\
\hline $14 / 465$ & $\mathrm{~F}$ & 26 & HRZSE & 4 & + & - & 2 & 1 & 20 & 4 & 18 & 3 & 118 & 128 & 62 & 67 & 20 & 10 & 1.32 & 0.12 \\
\hline $15 / 519$ & $\mathrm{M}$ & 33 & HRZSE & 3 & + & - & 4 & 1 & 18 & 10 & 9 & 4 & 118 & 120 & 69 & 73 & 20 & 10 & 1.32 & 0.12 \\
\hline $16 / 613$ & $M$ & 35 & HRZSE & 1 & + & - & 2 & 0 & 22 & 5 & 14 & 4 & 112 & 128 & 71 & 75 & 25 & 10 & 1.62 & 0.12 \\
\hline $17 / 654$ & $M$ & 38 & HRZSE & 1 & + & - & 3 & 0 & 34 & 9 & 14 & 8 & 122 & 130 & 68 & 77 & 25 & 10 & 1.62 & 0.12 \\
\hline $18 / 311$ & $M$ & 42 & HRZSE & 1 & + & - & 2 & 1 & 14 & 5 & 18 & 6 & 128 & 132 & 70 & 75 & 25 & 10 & 1.62 & 0.12 \\
\hline $19 / 558$ & $\mathrm{~F}$ & 41 & HRZSE & 2 & - & - & 3 & 0 & 38 & 11 & 18 & 4 & 112 & 118 & 59 & 70 & 20 & 10 & 2.35 & 0.12 \\
\hline $20 / 641$ & $M$ & 26 & HRZSE & 3 & + & - & 5 & 2 & 48 & 16 & 13 & 6 & 102 & 118 & 77 & 85 & 20 & 10 & 1.32 & 0.12 \\
\hline \multirow[t]{2}{*}{20} & $5 / 15$ & \begin{tabular}{|l|}
36.1 \\
\pm 10.6 \\
\end{tabular} & & & 17 & 1 & \begin{tabular}{|l|}
3.5 \\
\pm 1.4 \\
\end{tabular} & $\begin{array}{l}0.95 \\
\pm 1.1 \\
\end{array}$ & \begin{tabular}{|l|}
32.3 \\
\pm 11.4 \\
\end{tabular} & \begin{tabular}{|l|}
9.9 \\
\pm 6.4 \\
\end{tabular} & $\begin{array}{l}14.3 \pm \\
3.9 \\
\end{array}$ & \begin{tabular}{|l|}
$4.7 \pm$ \\
1.4 \\
\end{tabular} & \begin{tabular}{|c|}
114 \\
\pm 7.1 \\
\end{tabular} & $\begin{array}{l}123.4 \\
\pm 6.6 \\
\end{array}$ & \begin{tabular}{|l|}
65.3 \\
\pm 8.1 \\
\end{tabular} & \begin{tabular}{|l|}
73 \\
\pm 9.6 \\
\end{tabular} & \begin{tabular}{|l|}
22.1 \\
\pm 3.4 \\
\end{tabular} & $\begin{array}{r}10.9 \\
\pm 2.5 \\
\end{array}$ & \begin{tabular}{|l|}
1.72 \\
\pm 0.34 \\
\end{tabular} & \begin{tabular}{|l|}
0.18 \\
\pm 0.3 \\
\end{tabular} \\
\hline & & & & \begin{tabular}{|l} 
Mean: \\
2.95 \\
Median: \\
3
\end{tabular} & \multicolumn{2}{|c|}{$\begin{array}{l}\text { Fisher's } \\
\text { exact 2-way } \\
\text { test } \\
\mathrm{P}<0.000001\end{array}$} & \multicolumn{2}{|c|}{$\begin{array}{l}\text { Mean } \\
\text { decrease } \\
2.55 \mathrm{~cm} \\
P=2.893 \mathrm{E}- \\
009\end{array}$} & \multicolumn{2}{|c|}{$\begin{array}{l}\text { Mean } \\
\text { decrease } \\
22.4 \\
P=3.713 E \\
-008\end{array}$} & \multicolumn{2}{|c|}{$\begin{array}{l}\text { Mean } \\
\text { decrease } \\
9.6 \times 10^{9} \mathrm{~L} \\
\mathrm{P}=7.162 \mathrm{E}- \\
010\end{array}$} & \multicolumn{2}{|c|}{$\begin{array}{l}\text { Mean } \\
\text { gain } \\
9.3 \mathrm{~g} / \mathrm{L} \\
P=1.419 \mathrm{E}- \\
007\end{array}$} & \multicolumn{2}{|c|}{$\begin{array}{l}\text { Mean } \\
\text { gain } \\
7.7 \mathrm{~kg} \\
\mathrm{P}=4.604 \mathrm{E}- \\
007\end{array}$} & \multicolumn{2}{|c|}{$\begin{array}{l}\text { Mean } \\
\text { decrease } \\
11.2 \mu \mathrm{mol} / \mathrm{L} \\
P=5.679 \mathrm{E}- \\
009\end{array}$} & \multicolumn{2}{|c|}{$\begin{array}{l}\text { Mean } \\
\text { decrease } \\
1.54 \\
\mu \mathrm{mol} / \mathrm{ml} \cdot \mathrm{h} \\
\mathrm{P}=5.027 \mathrm{E}- \\
012 \\
\end{array}$} \\
\hline
\end{tabular}

${ }^{*} \mathrm{ALT}$ activity was determined according to Reitman \& Frankel [25]; the normal range of ALT in this test is $0.1-0.68 \mu \mathrm{mol} / \mathrm{ml} \cdot \mathrm{h}$

Table 1: Baseline and outcome characteristics of HCV-infected patients with HIV and TB co-infections treated with TB drugs in combination with V5 for one month. 
Citation: Arjanova OV, Prihoda ND, Yurchenko LV, Sokolenko NI, Frolov VM, et al. (2010) Phase 2 Trial of V-5 Immunitor (V5) in Patients with Chronic Hepatitis C Co-infected with HIV and Mycobacterium tuberculosis. J Vaccines Vaccin 1: 103. doi:10.4172/2157-7560.1000103

principles with old-fashioned killed vaccines, e.g., Hepatitis B vaccine made from pooled plasma. V5 is currently approved in Ukraine as an immunomodulating supplement. V-5 Immunitor is presented as an $850 \mathrm{mg}$ coated pill, ten of which are sealed in a "blister" pallet, with 30 pills per one package. The recommended dose is one to two pills per day. The preparation is stable at ambient temperature for five years.

\section{Administration schedule and monitoring}

The patients with confirmed pulmonary TB were treated with WHO-recommended regimen of antibiotics, i.e., Izoniazid (H) 300 mg; Rifampicin (R) 600mg; Pyrazinamide (Z) 2,000 mg; Streptomycin (S) $1,000 \mathrm{mg}$; and Ethambutol (E) $1,200 \mathrm{mg}$ in combination with one daily tablet of V5, which was given half-an-hour before or after the morning meal. The treatment was administered in an inpatient setting to patients hospitalized in our dispensary. The baseline and outcome parameters were established at study entry and at the end of follow-up. The ALT and other biochemical values were measured by routine lab methods. Rapid test kits for anti-HCV and HIV antibodies were from ACON Biotech (Hangzhou, PRC). In addition to clinical and biochemistry evaluations a standard microbiology examination of sputum smear staining by Ziehl Neelsen method was conducted prior to study entry and at post-treatment period.

\section{Statistical analysis}

Primary endpoints for this study were changes in serum ALT transaminase, total bilirubin, liver size, and clinical response. Secondary endpoints were parameters related to TB infection. Parametric values were assessed by paired Student t-test and qualitative changes were analyzed by Fisher's two-way contingency table using internet-based free software (GraphPad Software, Inc., La Jolla, CA). The significance level was set at $\mathrm{P} \leq 0.05$.

\section{Results}

The results of adjunct V5 immunotherapy which lasted one month are shown in Table 1 . The statistical values from paired $\mathrm{t}$-tests, provided at the bottom of the Table 1 , show that $\mathrm{V} 5$ produced significant positive changes. Without exception every endpoint of the study had reached highly significant statistical $P$ value compared to baseline, indicating that these parameters were correlated with each other and associated with better clinical outcome.

\begin{tabular}{|c|c|c|}
\hline Patient No & $\begin{array}{c}\text { Baseline } \\
\text { temperature }\left({ }^{\circ} \mathrm{C}\right)\end{array}$ & $\begin{array}{c}\text { Days to normal } \\
\left(36.8^{\circ} \mathrm{C}\right) \text { axillary temperature }\end{array}$ \\
\hline 1 & 37.5 & 5 \\
\hline 2 & 38 & 7 \\
\hline 3 & 38 & 2 \\
\hline 4 & 38 & 2 \\
\hline 5 & 38 & 7 \\
\hline 6 & 38 & No change \\
\hline 7 & 38 & 7 \\
\hline 8 & 38 & 10 \\
\hline 9 & 37 & 3 \\
\hline 10 & 37.5 & 4 \\
\hline 11 & 37.5 & 3 \\
\hline 12 & 38 & 4 \\
\hline 13 & 38 & 2 \\
\hline 14 & 37.5 & 2 \\
\hline 15 & 37.5 & 3 \\
\hline 16 & 38 & 2 \\
\hline 17 & 38 & 4 \\
\hline 18 & 38 & 6 \\
\hline 19 & 37.5 & Mean=4.1 Median=3 \\
\hline 20 & 38.5 & \\
\hline & Mean 37.8 Med= 38 & 2 \\
\hline
\end{tabular}

Table 2: The time to body temperature normalization.
The beneficial effect of V5 on hepatitis is supported by all three liver damage endpoints including normalization in ALT and bilirubin levels and decrease in abnormal liver size. Indeed the observed reduction was highly significant, from $1.72 \pm 0.34$ to $0.18 \pm 0.3 \mu \mathrm{mol} /$ $\mathrm{ml} \bullet \mathrm{h}(\mathrm{P}=5.0 \mathrm{E}-012)$ and $22.1 \pm 3.4$ to $10.9 \pm 2.5 \mu \mathrm{mol} / \mathrm{L}(\mathrm{P}=5.7 \mathrm{E}-009)$ for ALT and total bilirubin respectively. All, except one patient, noted disappearance of pain upon liver palpation. Enlarged liver reduced from $3.5 \pm 1.4$ to $0.95 \pm 1.1 \mathrm{~cm}$ above normal size $(\mathrm{P}=2.9 \mathrm{E}-009)$. This occurred despite the concurrent treatment of patients with antiTB drugs which are known to produce the adverse effect on liver function.

In addition, patients experienced remarkable amelioration in TBassociated inflammation indicators such as erythrocyte sedimentation rate, elevated leukocyte counts and persistent fever. After one month on V5 the erythrocyte sedimentation rate and leukocyte counts returned back to normal from $32.3 \pm 11.4$ to $9.9 \pm 6.4 \mathrm{~mm} / \mathrm{h}$ $(\mathrm{P}=3.7 \mathrm{E}-008)$ and $14.3 \pm 3.9$ to $4.7 \pm 1.4 \times 10^{9}$ cells/L $(\mathrm{P}=7.1 \mathrm{E}-010)$ respectively. Remarkably, TB-associated fever subsided in 19 out of 20 patients within mean/median $4.1 / 3$ days (Table 2 ). This was most likely due to V5 intervention since patients were on ATT for an average 3 months prior to the immunotherapy and despite that they had persistent above normal temperature.

Sputum smear examinations revealed that V5 appeared to accelerate the conversion rate. Out of 17 patients who were positive at baseline 16 individuals (94.4\%) became smear-negative after one month of adjunct immunotherapy. Other TB-associated symptoms such as anemia and weight loss have improved as a result of V5 intervention. The hemoglobin content increased from $114 \pm 7.1$ to $123.4 \pm 6.6 \mathrm{~g} / \mathrm{L}(\mathrm{P}=1.4 \mathrm{E}-007)$ and average body weight gain was 7.7 $\mathrm{kg}(\mathrm{P}=4.6 \mathrm{E}-007)$, range $4-13 \mathrm{~kg}$.

The most remarkable finding from the patients' perspective is the disappearance of baseline clinical symptoms after one month on V5 immunotherapy. Improved patients' well-being such as better quality of life, weight gain, increased appetite, enhanced physical strength, better mood, and other subjective parameters have been undeniable but were difficult to assess objectively. Only one patient (\#7), failed to respond fully to the therapy and this impression is corroborated by clinical and laboratory data. Based on sputum conversion and clinical improvement 17 out 20 patients were discharged from the hospital after one month and remaining three continued receiving further treatment.

\section{Discussion}

Open-label, one-month, phase 2 trial of V5 administered orally once per day revealed normalization of biochemical markers of hepatitis and remarkable clinical improvement among 19 out of 20 patients with chronic hepatitis $\mathrm{C}$. These findings support our earlier clinical investigations in two unrelated chronic hepatitis diseases, namely hepatitis B and C $[4,5]$. V5 was found to be safe and had reversed the signs of liver damage. This observation is significant since anti-TB drugs are prone to cause hepatotoxicity, especially among those with chronic hepatitis [9]. Thus, the hepatoprotective property of V5 could be advantageous even to those individuals who are treated with ATT, but do not have the underlying viral hepatitis. From prior experience with V5 we know that HCV viral burden can be reduced as a result of therapeutic vaccination [3]. However, due to financial constraints we were not able to measure HCV RNA in this study and thus we do not have information about the effect of V5 on viral load in this population of patients. We need to conduct additional studies to find this out. 
Several therapeutic vaccination strategies are now being explored for hepatitis C [3]. These include DNA immunization, peptide-based vaccines, plant-expressed vaccines, virus-like particles, and presentation of HCV antigens via dendritic cells. In addition to academic and non-profit institutions several biotech companies are involved in the development of therapeutic HCV vaccines. Most vaccines from these companies are in the preclinical stage. A few vaccines like TG4040 (Transgene); PeviPRO (Pevion); ChronVac-C (Inovio/Tripep); GI-5005 (Globelmmune); and HCV/MF59 (Chiron/ Norvartis) have advanced into safety phase 1 stage. Only three vaccines have been tested in advanced efficacy trials but have failed to reach study endpoints and were subsequently abandoned [3]. The therapeutic vaccine most relevant to this study is an oral preparation made from protein extract of human hepatocytes mixed with NS3 protein of HCV. This vaccine, which was developed by Yaron Ilan and his team with support of ENZO company, has shown good safety profile in phase 1 trial [10].

The postulated mechanism of Ilan et al., vaccine is similar to that of V5. The mucosal or oral administration of viral antigens entails a complex immune tolerance state, characterized by simultaneous enhancement and suppression of different elements of the immune response in a manner that benefits the host. Such a manipulation of the mucosal immune response against viruses may achieve a combination of specific anti-viral immunity and inhibition of immune-mediated liver injury. Since HCV is not cytopathogenic very little is known as to how the liver becomes damaged as a result of viral infection [1]. We subscribe to the theory that progressive liver injury is caused by self-directed immune reaction of certain $T$ cell subsets against virusinfected hepatocytes. Although the autoimmune nature of liver injury has been recognized by some investigators, others maintained that virus-induced autoimmune reaction in hepatitis is a rare event [3]. Nevertheless, it is clear that elevated serum aminotransferases and other hepatic injury markers, e.g., bilirubin, are definitively the signs of ongoing inflammatory liver damage associated with HCV.

In our opinion, a similar concept is applicable to $\mathrm{TB}$, whereby pulmonary or other tissues harboring mycobacteria are constantly assaulted by host's immune system, creating an inflammatory state and tissue damage akin to hepatitis. Thus, in order to treat these diseases one needs to induce specific immune tolerance rather than overdriving an already intense immune response [11]. However, there are practically no clinical studies that have addressed the immunological basis of TB infection from such a viewpoint [12]. Immunosuppressive regimens like adjunctive use of corticosteroids or TNF blockers have produced conflicting results suggesting that wholesale suppression of the immunity is fraught with risks of exacerbating the disease [12-15].

Currently available TB chemotherapy is not perfect; it requires several TB drugs to be taken in combination for long periods of time [6-8]. This can cause multiple side effects, poor drug adherence, treatment failure, and the emergence of drug resistance with major social and economic consequences, especially in low-income countries. It is agreed that novel immune-based therapies and TB vaccines are urgently needed to complement antitubercular drug discovery [16-18]. We also believe that the immunotherapy is ought to be the indispensable part of therapeutic strategies against TB. A large spectrum of diverse immunomodulators has been described for treatment of TB and hepatitis [19]. While some have shown clinical utility, in most cases their mechanism is not well understood. This drawback should be balanced against safety and therapeutic benefits [12-19].
Conversion of sputum smear from positive to negative is considered as a critical endpoint of the efficacy of anti-TB intervention. TB cases, especially those present with concomitant HIV and HCV infections are extremely difficult to treat [2]. Excessively lengthy treatment duration and low success rates are common in these patients. In the past we have conducted several clinical trials of ATT in TB/HIV co-infected patients and based on this experience we were not expecting sputum conversion rate better than 9-25\% after 6 months of continuous treatment. The present results reveal that when V5 is used together with ATT it can enhance the effect of TB drugs resulting in rapid sputum conversion in $94.4 \%$ of patients. Such an outcome is clearly unprecedented and surpasses the effect of immunomodulators we have tested in our prior studies [6-8]. Other improvements indicative of beneficial outcome were drastic weight gain and increase in hemoglobin levels. As a result 17 out 20 patients $(85 \%)$ were discharged from the hospital after one month.

What is the rational explanation to the effect of V5? This vaccine is derived from pooled blood of HCV+ and HBV+ donors. It is well known that one-third of the world population harbor latent Mycobacterium tuberculosis meaning that V5 preparation contains TB bacterium present in donors' blood. Therefore, the administration of V 5 could have triggered the immune response not only to hepatitis viruses but also to tubercle bacilli. Whether this is true needs to be verified by producing a vaccine candidate devoid of hepatitis viruses but containing $\mathrm{M}$. tuberculosis. To the best of our knowledge, the only orally available, heat-killed therapeutic TB vaccine that has shown promise in clinical studies is a preparation of Mycobacterium vaccae (SRL172) discovered and developed by Stanford et al., [20]. Most TB vaccines that have recently entered clinical trials stage are predominantly for prophylactic use and thus there is very little information available in the literature regarding their potential in treating TB [21-23].

Placebo-controlled trial is thus needed to confirm our findings and rule out non-specific factors that might have confounded the effect of V5. Despite the small number of enrolled subjects and short duration of the therapy the changes seen with every clinical endpoint were highly significant. The time to clear-cut clinical benefit appears to be only one month and, perhaps, even less as suggested for example by fever normalization within few days. Considering that conventional hepatitis and TB therapies require protracted treatment periods, which can often last longer than one year, the observed dynamics of response to the therapy is remarkable and gives us a hope that in the future the duration of therapy can be shortened substantially compared to current standards. Drug-resistant TB and HIV co-infection are two major obstacles preventing the efficient management of the disease [24]. V5 can be an ideal tool against these complications since it performs equally well compared to ordinary TB and there were no significant differences in treatment duration or outcome.

In conclusion, our results indicate that one tablet of V5 administered daily can produce clinical effects seldom seen in prior therapeutic vaccine trials. Hepatitis treatment options in developing countries such as Ukraine are extremely limited due to the high cost of medications. A therapeutic vaccine derived from readily available source certainly represents an affordable means to control chronic $\mathrm{HCV}$ infection and TB at the same time. Additional studies are warranted to develop better understanding of V5 properties and to enlarge the current arsenal of safe and effective immunotherapies. 
Citation: Arjanova OV, Prihoda ND, Yurchenko LV, Sokolenko NI, Frolov VM, et al. (2010) Phase 2 Trial of V-5 Immunitor (V5) in Patients with Chronic Hepatitis C Co-infected with HIV and Mycobacterium tuberculosis. J Vaccines Vaccin 1: 103. doi:10.4172/2157-7560.1000103

Page 5 of 5

\section{Acknowledgements}

We thank all volunteers who participated in this study. The wholehearted support of clinicians, nurses and lab personnel who contributed their effort made this study possible. We are grateful to our colleagues in Asia and Africa who shared their experiences relating to the present study.

\section{References}

1. Forde KA, Reddy KR (2009) Hepatitis C virus infection and immunomodulatory therapies. Clin Liver Dis 13: 391-401.

2. Ungo JR, Jones D, Ashkin D, Hollender ES, Bernstein D, et al. (1998) Antituberculosis drug-induced hepatotoxicity. The role of hepatitis $C$ virus and the human immunodeficiency virus. Am J Respir Crit Care Med 157: 18711876.

3. Batdelger D, Dandii D, Dahgwahdorj Y, Erdenetsogt E, Oyunbileg J, et al. (2009) Clinical experience with therapeutic vaccines designed for patients with hepatitis. Curr Pharm Des 15: 1159-1171.

4. Batdelger D, Dandii D, Jirathitikal V, Aldar S, Bourinbaiar AS et al. (2007) Open label trial of therapeutic hepatitis B vaccine V-5 Immunitor (V5) delivered by oral route. Lett Drug Des Discov 4: 540-544.

5. Batdelger D, Dandii D, Jirathitikal V, Bourinbaiar AS (2008) Open label trial of therapeutic immunization with oral V-5 Immunitor (V5) vaccine in patients with chronic hepatitis C. Vaccine 26: 2733-2737.

6. Prihoda ND, Arjanova OV, Yurchenko LV, Sokolenko NI, Vihrova LA et al. (2008) Adjuvant immunotherapy of tuberculosis in drug-resistant TB and TB/ HIV co-infected patients. Intl J Biomed Pharm Sci 2: 59-64.

7. Arjanova OV, Prihoda ND, Yurchenko LV, Sokolenko NI, Vihrova LA, et al. (2009) Enhancement of the efficacy of tuberculosis drugs with oral immunomodulator Dzherelo (Immunoxel) in HIV-infected patients with active pulmonary tuberculosis. Immunotherapy 1: 549-556.

8. Arjanova OV, Prihoda ND, Sokolenko NI, Yurchenko LV, Vihrova LA, et al. (2009) Impact of adjunct immunotherapy with multi-herbal supplement Dzherelo (Immunoxel) on treatment outcomes in end-stage TB/HIV patients. J Antivir Antiretrovir 1: 86-88.

9. Saukkonen JJ, Cohn DL, Jasmer RM, Schenker S, Jereb JA, et al. (2006) An official ATS statement: hepatotoxicity of antituberculosis therapy. Am J Respir Crit Care Med 174: 935-952.

10. Israeli E, Safadi R, Melhem A, Pappo O, Shibolet O, et al. (2004) Induction of oral immune regulation towards liver-extracted proteins for treatment of chronic HBV and HCV hepatitis: results of a phase I clinical trial. Liver Int 24: 295-307.
11. Ellner JJ (2010) Immunoregulation in TB: observations and implications. Clin TransI Sci 3: 23-28.

12. Churchyard GJ, Kaplan G, Fallows D, Wallis RS, Onyebujoh P, et al. (2009) Advances in immunotherapy for tuberculosis treatment. Clin Chest Med 30 769-82.

13. Smego RA, Ahmed N (2003) A systematic review of the adjunctive use of systemic corticosteroids for pulmonary tuberculosis. Int $\mathrm{J}$ Tuberc Lung Dis 7: 208-213.

14. Mayanja-Kizza H, Jones-Lopez E, Okwera A, Wallis RS, Ellner JJ, et al. (2005) Immunoadjuvant prednisolone therapy for HIV-associated tuberculosis: a phase 2 clinical trial in Uganda. J Infect Dis 191: 856-865.

15. Wallis RS, Schluger NW (2010) Pulmonary infectious complications of tumor necrosis factor blockade. Infect Dis Clin North Am 24: 681-692.

16. Kaufmann SH (2006) Tuberculosis: back on the immunologists' agenda. Immunity 24: 351-357.

17. Tomioka $\mathrm{H}$ (2004) Adjunctive immunotherapy of mycobacterial infections. Curr Pharm Des 10: 3297-3312.

18. Svenson S, Källenius G, Pawlowski A, Hamasur B (2010) Towards new tuberculosis vaccines. Hum Vaccin 6: 309-317.

19. Silin DS, Lyubomska OV, Ershov FI, Frolov VM, Kutsyna GA. (2009) Synthetic and natural immunomodulators acting as interferon inducers. Curr Pharm Des 15: $1238-1247$.

20. Dlugovitzky D, Notario R, Martinel-Lamas D, Fiorenza G, Farroni M, et al. (2010) Immunotherapy with oral, heat-killed, Mycobacterium vaccae in patients with moderate to advanced pulmonary tuberculosis. Immunotherapy 2: 159-169.

21. Beresford B, Sadoff JC (2010) Update on research and development pipeline: tuberculosis vaccines. Clin Infect Dis 50: S178-183.

22. Parida SK, Kaufmann SH (2010) Novel tuberculosis vaccines on the horizon. Curr Opin Immunol 22: 374-384.

23. Ochsner EH (1909) Vaccine therapy in joint tuberculosis. South Med J 2: 445450.

24. Laurenzi M, Ginsberg A, Spigelman M (2007) Challenges associated with current and future TB treatment. Infect Disord Drug Targets 7: 105-119.

25. Reitman S, Frankel S (1957) A colorimetric method for the determination of serum glutamic oxalacetic and glutamic pyruvic transaminases. Am J Clin Pathol 28: 56-63. 